\title{
Comparative Analysis of Circular and Rectangular Reinforced Concrete Tanks Based on Economical Design Perspective
}

\author{
Abba Mas'ud Alfanda ${ }^{1}$, Abdulwarith Ibrahim Farouk ${ }^{2}$ \\ ${ }^{1}$ Civil Engineering Department, Fatih University, Istanbul, Turkey \\ ${ }^{2}$ Civil Engineering Department, University of Technology, Johor Bahru, Malaysia
}

Email address:

meetabba22@yahoo.co.uk (A. Mas'ud Alfanda), aifg1986@gmail.com (A. I. Farouk)

\section{To cite this article:}

Abba Mas'ud Alfanda, Abdulwarith Ibrahim Farouk. Comparative Analysis of Circular and Rectangular Reinforced Concrete Tanks Based on Economical Design Perspective. American Journal of Applied Scientific Research. Vol. 3, No. 2, 2017, pp. 14-20.

doi: 10.11648/j.ajasr.20170302.12

Received: March 2, 2017; Accepted: March 22, 2017; Published: October 31, 2017

\begin{abstract}
The need for a water tank is as old as civilization, to provide storage of water for use in many applications. Design and cost estimation of water tanks is a time consuming task, which requires a great deal of expertise. All tanks are designed as crack free structure to eliminate any leakage. This project therefore studies the efficiency of rectangular or circular tanks, 40,000 liters capacities were used in order to draw reasonable inferences on tanks shape design effectiveness, relative cost implications of tank types and structural capacities. The basic tanks construction materials include steel reinforcement, concrete and formwork obtained from the prepared structural drawings. Result of the materials take-off revealed that circular tank consumed lesser individual materials as compared to rectangular one. This will give circular shaped tanks more favored selection over the rectangular shaped tank, although some other factors must still be assessed.
\end{abstract}

Keywords: Reinforced Concrete, Steel Reinforcement, Water Tank, Formwork

\section{Introduction}

Water is considered as the source living for every creation as it is a crucial element for healthy living. Safe drinking water is one of the basic elements for human to sustain a healthy life. High demand for safe and clean water is rising day by day as one cannot live without water. Thus, it becomes necessary to store water, water is stored generally in concrete water tanks and later on it is pumped to different areas to serve community.

An extensive literature review reveals that a minimum amount of research works had been done on this topic, especially in Nigeria. [1] Rationalized the design procedure for reinforced and pre-stressed concrete tanks so that an applicable Canadian design standard could be developed. The study investigates the concept of partial pre-stressing in liquid containing structures. The paper also includes experimental and analytical phases of total of eight full scale specimens, representing segments from typical tank walls, subjected to load and leakage tests. In analytical study a computer model that can predict the response of tank wall segments is described and calibrated against the test results. The proposed design procedure addresses the leakage limit state directly. It is applicable for fully pre-stressed, fully reinforced and partially pre-stressed concrete water tanks. The conclusions that are drawn are as follows:

i. A design method based on limiting the steel stress, does not produce consistent crack or compression zone depths under the application of pre-stressing nor under a combination of axial load and moment.

ii. A design method based on providing a residual compressive stress in concrete dose not utilizes nonpre-stressed reinforcement effectively.

iii. Relaxing the residual compressive stress requirement permits a more efficient design. The stresses in nonpre-stressed steel are higher, but remain below yield under service load. Therefore, less reinforcement is required. 
iv. Load eccentricity significantly affects the behavior of the pre-stressed concrete sections. The behavior with a small load eccentricity, less than about half the thickness, the section may be treated as a flexure member.

v. The ratio of non pre-stressed steel to pre-stressed steel in partially pre-stressed concrete section has a significant effect on the member serviceability and strength. Choosing the ratio such that both non- prestressed and pre-stressed steel reach their strength simultaneously utilizes both types of steel at the ultimate limit state effectively.

vi. Increasing the wall thickness is very effective in increasing the capacity of the section and improving its serviceability by increasing the compression zone depth and reducing the deformations.

Another Study was done on cost optimization of reinforced concrete circular grain silos based on the BS Code (2002) [2]. He proved that the minimum cost of the silo increases with increasing angle of internal friction between stored materials, the coefficient of friction between stored materials and concrete, and the number of columns supporting hopper. While [14] studied the economical design of concrete water Tanks by optimization method. He applied the optimization technique to the structural design of concrete rectangular and circular water tanks, [20] have brought out the revised version of BS 3370 (part 1 and 2) after a long time from its 1965 version in year 2009. This revised code is mainly drafted for the liquid storage tank.

\subsection{Need for Storage Tank}

Reservoir is a common term applied to liquid storage structure and it can be below or above the ground level. Reservoirs below the ground level are normally built to store large quantities of water whereas those of overhead type are built for direct distribution by gravity flow and are usually of smaller capacity.

Storage reservoirs and water tanks are used to store water, liquid petroleum, petroleum products and similar liquids. The force analysis of the reservoirs or tanks is about the same irrespective of the chemical nature of the product. All tanks are designed as crack free structures to eliminate any leakage. Water or raw petroleum retaining slab and walls can be of reinforced concrete with adequate cover to the reinforcement. Water and petroleum react with concrete and, therefore, no special treatment to the surface is required. Industrial wastes can also be collected and processed in concrete tanks with few exceptions.

The need for a water tank is as old as civilization, to provide storage of water for use in many applications. Water tanks can be classified as circular, rectangular, conical, depending on their location. The tanks can be made of steel or concrete. Tanks resting on ground are normally circular or rectangular in shape and are used where large quantities of water need to stored. Water tank parameters include the general design of the tank, and choice of construction materials and linings. Reinforced Concrete Water tank design depends based on the location of tanks. The tanks can be made of RCC or even of cylinder for corrosion protection and to form an interstitial space.

\subsection{Statement of Problem}

Reinforced concrete water tanks are used to store and supply safe drinking water. With the rapid speed of urbanization, demand for drinking water has increased by many folds. Also, as demand for water tanks will continue to increase in coming years, quick cost prediction of circular rectangular tanks before its design will be helpful in selection of tanks for real design. Quick cost prediction of tanks of different geometry and capacity is a difficult job and a time consuming task especially for less experienced design engineers [18], [17]. Many times it is required to know the cost of a tank of known capacity and geometry before its detailed design [24]. Many researchers such as [16], [14], [11], [9] and [18] have studied the stability and the economic aspects of water tank design.

\subsection{Significance of the Study}

This research is concern with the comparison between circular and rectangular reinforce concrete tanks. It attempted to achieve some measure of the best practical solutions, that is, the optimum design of reinforced concrete water tanks for a specified performance.

\subsection{Aim}

The major aim is to reveal the degree of effectiveness of the geometric shapes for the functional requirement, with the view to achieving adequate strength and economy.

\subsection{The Specific Objectives}

The specific objectives of the study are:

i. To make the analysis and design of water tank in accordance with BS8007code

ii. To compare the economical design of circular and rectangular reinforce concrete tank.

iii. To estimate the cost of construction of both circular and rectangular tanks and hence to access the possible cost implications of each choice.

\section{Methodology}

The design tool for circular and rectangular reinforced concrete water tanks was prompted by the rigorous and lengthy manual design of reinforced concrete water tank, fully dimensioned and listed in a schedule of the reinforcement which is used on site for the bending and fixing of the bars. Standard bar shapes and a method of scheduling were used as specified in BS8666, The British code of practice BS8007, which is a modification to BS8110, was also adopted as well. The principal features include:

i. The use of a factor of safety $\mathrm{Uf}=1.4$ for liquid loads.

ii. The use of concrete grade $\mathrm{C} 30$ (with a maximum water/cement ratio of 0.55 and a minimum cement 
content of $325 \mathrm{~kg} / \mathrm{m}^{3}$ that is, durability performance comparable to grade $\mathrm{C} 40$ ).

iii. The use of a minimum cover of $25 \mathrm{~mm}$ owing to assumed severe exposure condition on internal and at least one of both faces.

iv. Maximum crack width limited to $0.3 \mathrm{~mm}$ unless the aesthetic appearance is critical, when $0.1 \mathrm{~mm}$ is used to avoid staining of the concrete.

v. Maximum bar spacing of $300 \mathrm{~mm}$.

vi. For a wall thickness is exceeding $200 \mathrm{~mm}$ and floor thickness exceeding $300 \mathrm{~mm}$.

vii. Anchorage bond stress for straight horizontal bars in sections subjected to direct tension must be reduced to 70 per cent of the usual values.

viii. At least $75 \mathrm{~mm}$ blinding concrete is required below ground slabs.

\subsection{Design of Circular Reinforced Concrete Water Tank}

Step 1: Given data

Capacity of the tank $=40,000 \mathrm{~L}$

Depth of water $(\mathrm{h})=5.9-0.2=5.7 \mathrm{~m}$

Overall depth $(\mathrm{H})=5.9 \mathrm{~m}$

Volume of water $(\mathrm{V})=40,000 / 1000=40 \mathrm{~m}^{3}$

Concrete cover $=0.25 \mathrm{~m}$

Free board $=0.2 \mathrm{~m}$

Concrete grade $=$ Reinforcement Fe415

Step 2: Determination of tank diameter

$$
\begin{aligned}
& \mathrm{A}=\frac{40}{5.7}=7.0175 \approx 7.018 \mathrm{~m}^{2} \\
& \mathrm{D}=\sqrt{\frac{4 \mathrm{~A}}{\pi}}=\frac{4 \times 7.018}{3.143}=3 \approx 3 \mathrm{~m}
\end{aligned}
$$

Step 3: Analysis of hoop tension and bending moment

One meter width of the wall is considered as the thickness of the wall is estimated as:

$\mathrm{t}=30 \mathrm{H}+50=30 \times 5.7+50=221 \mathrm{~mm}$

The thickness of the wall is assumed as $230 \mathrm{~mm}$

$\therefore$ Maximum hoop tension $T_{\text {Max }}=0.575 \times \frac{w H D}{2}=0.575$ $\times \frac{10 \times 5.7 \times 3}{2}=49 \mathrm{KN}$

Maximum bending moment $M_{\text {Max }}=0.0146 \times \mathrm{wH}^{3}=$ $0.0146 \times 10 \times 5.7^{3}=27 \mathrm{KNm}$

Step 3: Design of section

Permissible compressive stress in concrete $\sigma_{c b c}=7 \mathrm{~N} / \mathrm{mm}^{2}$

Permissible compressive stress in steel $\sigma_{s t}=150 \mathrm{mpa}$

Modular ratio $=\mathrm{M}=13.33$

Design constants are:

$$
\begin{gathered}
\mathrm{K}=\frac{M \times \sigma_{c b c}}{M \times \sigma_{c b c}+\sigma_{s t}}=\frac{13.33 \times 7}{13.33 \times 7+150}=0.39 \\
\mathrm{~J}=1-\left(\frac{K}{3}\right)=1-\left(\frac{0.39}{3}\right)=0.87 \\
\mathrm{Q}=\frac{1}{2} \sigma_{c b c} \mathrm{JK}=\frac{1}{2} \times 7 \times 0.87 \times 0.39=1.19
\end{gathered}
$$

Effective depth $=\mathrm{d}=\sqrt{\frac{M_{M a x}}{Q b}}=\sqrt{\frac{27.038 \times 10^{6}}{1.19 \times 1000}}=150.73 \approx$ $151 \mathrm{~mm}$

Let the overall thickness be $230 \mathrm{~mm}$ with effective cover of
$25 \mathrm{~mm}$

$$
\begin{gathered}
\therefore d_{\text {provided }}=230-25=205 \mathrm{~mm} \\
A_{s t}=\frac{M_{\text {Max }}}{\sigma_{s t} J d}=\frac{27.038 \times 10^{6}}{150 \times 0.87 \times 205}=1010.52 \mathrm{~mm}^{2}
\end{gathered}
$$

Spacing of $16 \mathrm{~mm}$ diameter bar $=\frac{201 \times 1000}{1010.52}=198.907 \approx$ 200mmc/c

Provided $\#_{16 \mathrm{~mm}} @ 200 \mathrm{mmc} / \mathrm{c}$ as vertical reinforcement on water face

$$
\text { Hoop steel }=A_{s t 1}=\frac{T_{M a x}}{\sigma_{s t}}=\frac{147.488 \times 10^{3}}{150}=983.25 \mathrm{~mm}^{2}
$$

Spacing of $12 \mathrm{~mm}$ diameter bar $=\frac{113 \times 1000}{983.25}=114.92 \approx$ $110 \mathrm{mmc} / \mathrm{c}$

Provided $\#_{12 \mathrm{~mm}} @ 110 \mathrm{mmc} / \mathrm{c}$ as hoop reinforcement on water face

Actual area of steel provided $=A_{s t}=\frac{113 \times 1000}{110}=$ $1027.3 \mathrm{~mm}^{2}$

Step 4: Check for tensile stress

$$
\begin{array}{r}
\sigma_{c}=\frac{T_{\operatorname{Max}}}{1000 t+(m-1) A_{s t}}=\frac{147.488 \times 10^{3}}{1000 \times 230+(13.33-1) \times 1027.3}= \\
0.61 \mathrm{~N} / \mathrm{mm}^{2}
\end{array}
$$

Permissible stress $=1.2 \mathrm{~N} / \mathrm{mm}^{2}>0.61 \mathrm{~N} / \mathrm{mm}^{2}$ safe

Step 5: Top slab

The thickness of top slab shall be 150 since there is no load or stresses on it, minimum area of steel is $0.24 \%$ of concrete area should be provided

$$
\therefore A_{s t}=\frac{0.24}{100} \times b \times t=\frac{0.24}{100} \times 1000 \times 150=360 \mathrm{~mm}^{2}
$$

Reinforcement for each face $=180 \mathrm{~mm}^{2}$

Spacing of $8 \mathrm{~mm}$ diameter bar $=\frac{50.24 \times 1000}{180}=279 \mathrm{mmc} / \mathrm{c}$

Provide $\#_{8 \mathrm{~mm}}$ @250mmc/c as vertical and horizontal distribution steel

Step 6: Base slab

The thickness of base shall be $150 \mathrm{~mm}$ the base rests on firm ground; hence only minimum reinforcement is provided

$$
\therefore A_{s t}=\frac{0.24}{100} \times b \times t=\frac{0.24}{100} \times 1000 \times 150=360 \mathrm{~mm}^{2}
$$

Reinforcement for each face $=180 \mathrm{~mm}^{2}$

Spacing of $8 \mathrm{~mm}$ diameter bar $=\frac{50.24 \times 1000}{180}=279 \mathrm{mmc} / \mathrm{c}$

Provide $\#_{8 \mathrm{~mm}} @ 250 \mathrm{mmc} / \mathrm{c}$ as vertical and horizontal distribution on the outer face

\subsection{Design of Rectangular Reinforced Concrete Water Tank}

Step 1: Given data

Capacity $=40,000 \mathrm{~L}=40 \mathrm{~m}^{3}$

Depth $=2.0 \mathrm{~m}$

Size $=4 \mathrm{~m} \times 5 \mathrm{~m}$

Free bore $=0.2 \mathrm{~m}$

Concrete $=\mathrm{M}_{20}$

Reinforcement $=$ Fe415

Step 2: Permissible stresses $\sigma_{c b}=7 \mathrm{~N} / \mathrm{mm}^{2}$ 
$\sigma_{s t}=100 \mathrm{~N} / \mathrm{mm}^{2}$ (on faces near water face)

$\sigma_{s t}=125 \mathrm{~N} / \mathrm{mm}^{2}$ (on faces away from water)

$\mathrm{M}=13, \mathrm{Q}=1.41, \mathrm{~J}=0.84$

Step 3: Dimension of the tank

Length $=\mathrm{L}=5 \mathrm{~m}$

Width $=\mathrm{B}=4 \mathrm{~m}$

Ratio $=\frac{L}{B}=\frac{5}{4}=1.25$

Step 4: designs of long walls and short walls

Long walls are designed as vertical cantilevers and short walls are spanning horizontally between long walls

Maximum bending moment at base of long wall

$$
M_{L}=\frac{w H^{3}}{6}=\frac{10 \times 2.2^{3}}{6}=17.75 \mathrm{KNm}
$$

Effective depth $=\mathrm{d}=\sqrt{\frac{M_{L}}{Q b}}=\sqrt{\frac{17.75 \times 10^{6}}{1.41 \times 1000}}=112.2 \approx 120 \mathrm{~mm}$

Using $16 \mathrm{~mm}$ diameter bars and $25 \mathrm{~mm}$ clear concrete cover Effective depth $=120 \mathrm{~mm}$

Overall depth $=160 \mathrm{~mm}$

$$
A_{s t}=\frac{M_{L}}{B J d}=\frac{17.75 \times 10^{6}}{1000 \times 0.84 \times 120}=186.99 \approx 176 \mathrm{~mm}^{2}
$$

Spacing of $16 \mathrm{~mm}$ diameter bar $=\frac{100 \times 201}{176}=114.2 \approx$ $120 \mathrm{~mm} \mathrm{c} / \mathrm{c}$

Provide \#16mm@120mm c/c toward the top

Intensity pressure $1 \mathrm{~m}$ above the top $=\mathrm{P}=w(H-h)=$ $10(2.2-1)=12 \mathrm{KN} / \mathrm{m}^{2}$

Direct tension in long walls $=T_{L}=\left(\frac{12 \times 2}{2}\right)=12 \mathrm{KN}$

$$
A_{\text {st } 1}=\frac{12 \times 10^{3}}{100}=120 \mathrm{~mm}^{2}
$$

But minimum area $=0.3 \%=\left(\frac{0.3}{100} \times 160 \times 1000\right)=$ $420 \mathrm{~mm}^{2}$

Spacing of $10 \mathrm{~mm}$ diameter bar $=\frac{1000 \times 79}{420}=188 \mathrm{~mm}$

Provided \#10mm@200mm c/c on both faces

Design for short walls:

Intensity pressure $1 \mathrm{~m}$ above the top $=\mathrm{P}=w(H-h)=$ $10(2.2-1)=12 \mathrm{KN} / \mathrm{m}^{2}$

Effective span of horizontally spanning slab $=(4+0.16)=$ $4.16 \mathrm{~m}$

Bending moment (corner section) $=M_{S}=\left(\frac{P L^{2}}{12}\right)=$ $\left(\frac{12 \times 4.16^{2}}{12}\right)=17.31 \mathrm{KNm}$

Tension transferred per meter height of short wall $=T_{S}=$ $(12 \times 1)=12 \mathrm{KN}$

$\therefore A_{s t}=\frac{M_{S}-T_{X}}{\sigma_{S t} \times J \times d}+\frac{T_{S}}{\sigma_{s t}}=\frac{17.31 \times 10^{6}-12 \times 10^{3}(113-100)}{100 \times 0.84 \times 113}+\frac{12 \times 10^{3}}{100}$

$=1927.21 \approx 1928 \mathrm{~mm}^{2}$

Spacing of $10 \mathrm{~mm}$ diameter bar $=\frac{1000 \times 79}{1928}=40.98 \mathrm{~mm}$

Provide $\#_{16 \mathrm{~mm}}$ bars at $40 \mathrm{~mm} \mathrm{c} / \mathrm{c}$ at mid-span section the bending moment is $P L^{2} / 24$ and hence $\#_{10 \mathrm{~mm}}$ diameter bars at $80 \mathrm{~mm} \mathrm{c} / \mathrm{c}$ away from water face.

Step 5: Design of cantilevering effect of short walls
Maximum bending moment $=B . M=\frac{1}{2} \times \frac{1}{3} w H=$ $\frac{1}{2} \times \frac{1}{3} \times 10 \times 2.0=3.333 \mathrm{KNm}$

Effective depth using $10 \mathrm{~mm}$ diameter $=\mathrm{d}=(160-25-10$ $-5)=120 \mathrm{~mm}$

$$
\therefore A_{s t}=\frac{3.333 \times 10^{6}}{100 \times 0.84 \times 120}=396.785 \approx 397 \mathrm{~mm}^{2}
$$

But $0.3 \%$ of gross area $=\left(\frac{0.3}{100} \times 160 \times 1000\right)=$ $480 \mathrm{~mm}^{2}$

Spacing of $10 \mathrm{~mm}$ diameter bar $=\frac{1000 \times 79}{480}=164.58 \mathrm{~mm}$

Provide $\#_{10 \mathrm{~mm}} @ 200 \mathrm{~mm} \mathrm{c} / \mathrm{c}$ both faces in the vertical direction

Step 6: Base slab

The thickness of base slab shall be $150 \mathrm{~mm}$ the base rests on firm ground; hence only minimum reinforcement is provided

$$
\therefore A_{s t}=\left(\frac{0.24}{100} \times 150 \times 1000\right)=360 \mathrm{~mm}^{2}
$$

Reinforcement for each face $=180 \mathrm{~mm}^{2}$

Spacing of $10 \mathrm{~mm}$ diameter bar $=\frac{1000 \times 79}{180}=438 \mathrm{~mm}$

Provide $\#_{10 \mathrm{~mm}} @ 400 \mathrm{~mm} \mathrm{c} / \mathrm{c}$ as vertical and horizontal distribution on the outer face.

\section{Result Presentation}

The summary for both circular and rectangular reinforced concrete tanks reinforcement is given in Table 1 and Table 2 respectively.

Table 1. Bar schedules for reinforced rectangular concrete tank.

\begin{tabular}{lllll}
\hline $\begin{array}{l}\text { Bar } \\
\text { reference }\end{array}$ & Bar shape & $\begin{array}{l}\text { Diameter } \\
(\mathbf{m m})\end{array}$ & $\begin{array}{l}\text { Length } \\
(\mathbf{m m})\end{array}$ & $\begin{array}{l}\text { Total number } \\
\text { of bar }\end{array}$ \\
\hline$\#_{16 \mathrm{~mm}}$ & Straight & 16 & 2716 & 198 \\
$\#_{16 \mathrm{~mm}}-A$ & Straight & 10 & 2560 & 89 \\
$\#_{16 \mathrm{~mm}}-B$ & Straight & 10 & 5210 & 48 \\
$\#_{16 \mathrm{~mm}}-C$ & U-shaped & 10 & 660 & 54 \\
$\#_{16 \mathrm{~mm}}-D$ & Straight & 10 & 4210 & 108 \\
$\#_{16 \mathrm{~mm}}-E$ & Straight & 10 & 2410 & 12 \\
$\#_{16 \mathrm{~mm}}-F$ & Straight & 10 & 4210 & 25 \\
$\#_{16 \mathrm{~mm}}-I$ & Straight & 10 & 5210 & 20 \\
\hline
\end{tabular}

Table 2. Bar schedules for reinforced concrete circular tank.

\begin{tabular}{lllll}
\hline Reference & Bar-shape & $\begin{array}{l}\text { Diameter } \\
(\mathbf{m m})\end{array}$ & $\begin{array}{l}\text { Number } \\
\text { of bar }\end{array}$ & $\begin{array}{l}\text { Length } \\
\text { (mm) }\end{array}$ \\
\hline \# & Circular/Hoop & 12 & 55 & 27930 \\
$\#$ & Straight & 16 & 298 & 5590 \\
\# - A & U-shape & 8 & 37 & 9050 \\
\# - B & U-shape & 8 & 39 & 9350 \\
\hline
\end{tabular}

The taking - off, abstract, bill of quantity and detailed calculations are shown in the appendices while the summary is shown in Table 3. 
Table 3. Bill of Quantities Summary.

\begin{tabular}{|c|c|c|c|c|}
\hline Items & Circular tank & & Rectangular tank & \\
\hline General clearance of top soil & $0.0144 \mathrm{ha}$ & $\$ 7200.00 \mathrm{k}$ & $0.003 \mathrm{ha}$ & N150.00k \\
\hline Excavation for foundation & $21.60 \mathrm{~m}^{3}$ & $\$ 172800.00 \mathrm{k}$ & $5.698 m^{3}$ & $\$ 45584.00 \mathrm{k}$ \\
\hline Provision of concrete & $58.99 \mathrm{~m}^{3}$ & $\$ 782240.00 \mathrm{k}$ & $12.141 \mathrm{~m}^{3}$ & $\$ 161211.00 \mathrm{k}$ \\
\hline Form work & $126.95 \mathrm{~m}^{2}$ & $\mathrm{~N} 334960.00 \mathrm{k}$ & $163.2 \mathrm{~m}^{2}$ & $\$ 42615.00 \mathrm{k}$ \\
\hline Reinforcement & $0.32204 \mathrm{t}$ & $\$ 111137.00 \mathrm{k}$ & $0.1277 \mathrm{t}$ & N90299.00k \\
\hline Total & & $1703287.00 \mathrm{k}$ & & $\$ 400564.00 \mathrm{k}$ \\
\hline
\end{tabular}

\section{Discussion}

Table 2 indicates that the quantities of materials need for the circular water tank were constantly more than those needed for the rectangular water tank at each varied capacity.

Assessing the relative reduction in the amounts of materials for the rectangular tanks, it was seen that the formwork would be significantly more challenged in the construction of the circular tanks, their presumed material quantity advantage could be given up for a selection of circular tank (through with potential increase in material requirement). This could be considered if the said reduction in materials is relatively small or variable. But, the final choice would depend on the client's desire and the advice of the professional taking off the job.

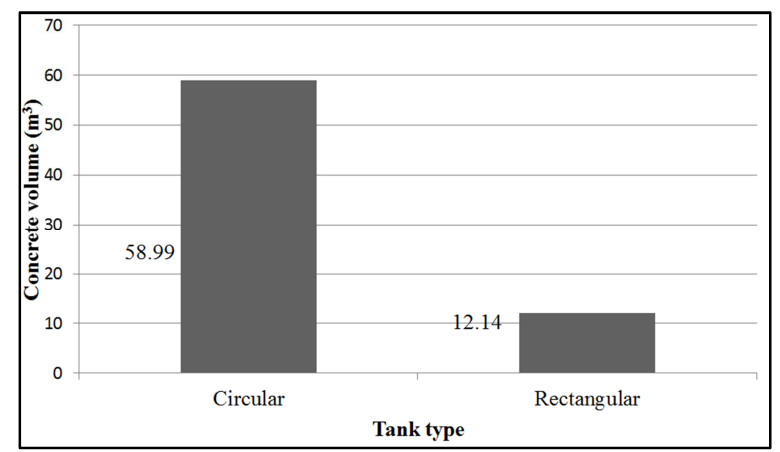

Figure 1. Concrete volume distribution chart.

From the Figure 1, although, both circular and rectangular water tanks have the same capacities but from the result, the amount of concrete in circular tank is greater than that of rectangular tank. Therefore it is advisable to use the rectangular tank in terms of cost but in case of resistance to all pressure exerted in the tank circular is better.

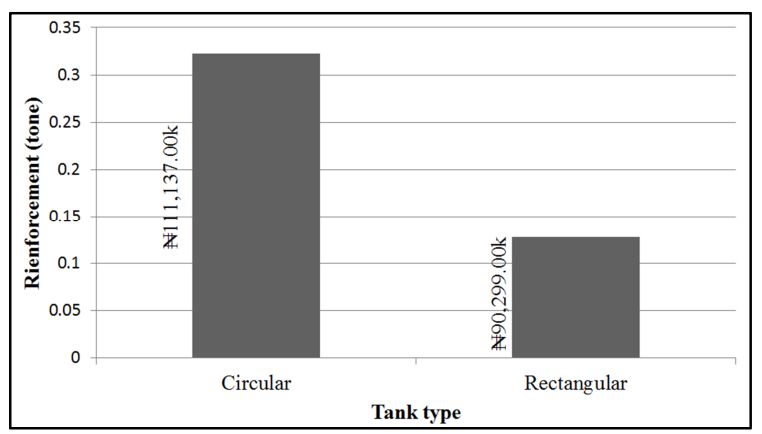

Figure 2. Reinforcement distribution chart.
Based on Figure 2, a circular tank is greater than rectangular tank with respect to their quantities of reinforcement. Both circular and rectangular water tanks have the same capacities but from the result design, the amount of reinforcement tonnage in circular tanks is greater than that of rectangular tank.

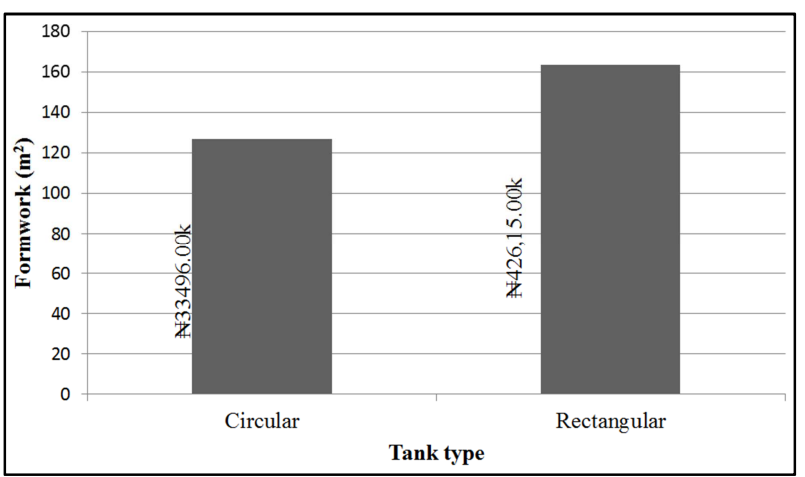

Figure 3. Formwork distribution chart.

According to Figure 3, both circular and rectangular water tanks have the same capacities however from the design output, the amount of formwork in meter square in rectangular tanks is greater than that of circular tank. In conclusion, circular tank has the higher quantities and amount in terms of concrete and reinforcement than that of rectangular tank. But rectangular tank is greater than circular tank in term of formwork. Moreover from the overall cost, the circular tank is greater than rectangular tank.

\subsection{Conclusion}

Generally, the construction material outputs for all water tanks shape would be based on the choice of the design considerations, with the size of their structural elements. Hence, there exists the possibility of having an equal capacity and similar geometrically shaped water tank but with some measurable difference in material requirement, for instance, a tank wall designed as a cantilever would come up with a relatively difference material quantity when compared with its material requirements. If designed as a two-way spanning wall (as for rectangular tank) or ring (or hoop) wall, (as for circular tank).

It can be clearly seen that materials needed for the construction of rectangular water tank is comparatively more than those required for circular one but ease of construction, is more difficult in circular water tank as compared to that of rectangular water tank. Hence it could be deduced that the 
outcome of tank design and the possible cost implication of its material requirements coupled with the relative ease of construction would be considered for the proposed water tank of any capacity although some other factors must still be assessed.

\subsection{Recommendation}

The research studies the comparison between circular and rectangular reinforced concrete tanks based economical design point of view. For future research, the following investigations are recommended:

i. Examination the response of reinforced concrete tanks under the effect of Hydrodynamic pressure resulting from earthquake loading.

ii. Failures of tanks should be investigated by using a computer program that considers cracking and nonlinearity.

iii. Additional experimental study of wall specimens subjected to both axial tensions and combined axial compression is needed.

\section{List of Symbols}

H: Overall depth

h: Depth of water

$\mathrm{V}$ : Volume

Fe: Reinforcement grade

A: Area

D: Diameter

t: Wall thickness

$T_{\text {Max }}$ : Maximum hoop tension

$M_{\text {Max }}$ : Maximum bending moment

$w$ : Weight of water

$\sigma_{c b c}$ : Permissible compressive stress in concrete

$\sigma_{s t}:$ Permissible compressive stress in steel

M: Modular ratio

K, J, Q: Design constants

d: Effective depth

$A_{s t}$ : Area of steel

\#: Steel type

$\approx:$ Approximation

$\sigma_{c}$ : Tensile stress

b: width

$M_{L}$ : Bending moment for long walls

$T_{L}$ : Direct tension for long walls

P: Intensity pressure

$M_{s}$ : Bending moment for short walls

$T_{s}$ : Tension transferred for short walls

B. M: Maximum bending moment

(a): at

c/c: Center to center

\section{References}

[1] Abdul Aziz \& A. Rashid "Water Tanks Design in Urban Spaces Designed for Optimal Use of Flowing Water from Precipitation Climate", International Journal of Modern
Engineering Research, Vol 1, Issue 2, Pp 418-424.

[2] Al-Badri (2005) "Application Evolutionary Global Optimization Techniques in the Design of RC Water Tanks" Engineering Structures, Pp 332-334.

[3] Anchor, R. D. (1981) "Design of Liquid Retaining Concrete Structure”. London Surrey university press.

[4] Anchor, R. D. (1992) "Design of Liquid Retaining Concrete Structure". Second edition London.

[5] BS 8007 (1987) code of practice for design of concrete structure for retaining aqueous liquids.

[6] BS 8110 part 1 (1997) code of practice for design and construction structural use of concrete.

[7] BS 8110 part 1 (2002) code of practice for design and construction structural use of concrete.

[8] BS 8110 part 1 (2007) code of practice for design and construction structural use or concrete.

[9] Charles, J. (2007) "Longtime Emblems of City Roofs, Still Going Strong" The New York Times.

[10] Durgesh, C. R. (2001) "Design of Differences Type of Tanks". Department of Civil Engineering, London Institute of Technology, London.

[11] Elliott, D. (2006) "Wondering About Water Towers" New York Times.

[12] Gray, W. S. and Manning, G. P. (1964) "Water Towers, Bunkers, Silos and Other Elevated Structures". London. Concrete Publications Limited.

[13] H. J. Mohammed (2011), "Economical Design of Water Concrete Tanks", European journal of scientific research vol. 49.

[14] Hassan Jasim Mohammed, "Economical Design of Water Concrete Tanks" Europeans Journal Publication, Vol 49 No. 4 (2011), Pp 510-520.

[15] Ludwig, A. (2008) “Tanks, Cisterns, Aquifers, and Ponds. For Domestic Supply, Fire and Emergency Use-Includes How to Make Ferro cement Water Tanks". www.oasisdesign.net

[16] Manning, G. P. (1967) "Reservoirs and Tanks"e. London. Concrete Publications Limited.

[17] Pall, A. and Pall, R. T. (2004) "Performance-Based Design Using Pall Friction Dampers- An Economical Design Solution". Paper No. 1955. 13th World Conference on Earthquake Engineering. Canada.

[18] Patentscope (1998) "Construction of Liquid Retaining Structures". www.wipo.int/patentscope/en/

[19] Pathak \& Agarwal, (2003) and Pall, (2004), "Cost Prediction of Overhead Water Tanks Using Artificial Neural Networks", IE (I) Journal, Vol. 84, pp. 153 - 158.

[20] R. K. Prasad \& Akshaya B. Kamdi (2012) "Recent Development in Structural Optimization" Journal of Structural Engineering, Vol 113 No. 9.

[21] Rao M L N (2000) Effect of confinement on ductility of RC hollow circular columns, a masters' thesis submitted to Dept. of Earthquake Eng., Univ. of Roorkee, Roorkee, India. 
[22] Reynolds, C. E. and Steedman, J. C. (1988) "Reinforced Concrete Designer's Handbook". Tenth Edition. London. E \& FN Spon.

[23] S. A. Raji "Window Base Computer Programs for Analysis and Design of Water Tank" Department of civil engineering university of Ilorin Nigeria.
[24] Slater, W. M. (1985) "Concrete Water Tanks in Ontario". Canadian Journal of Civil Engineering, Toronto.

[25] W. O, Ajagbe, S I. Adedokun and W. B. Oyesile W. B, Comparative study on the design of elevated rectangular and circular concrete water tanks, International Journal of Engineering Research and Development 1(1), 2012, 22-30. 